\title{
Modification of Crystallization Properties of Poly(ethylene terephthalate) by Copolymerization with Arylate-Units III. Bisphenol-A- and Bisphenol-S-Containing Copolymers
}

\author{
Yoshimitsu SAKAGUCHI \\ Toyobo Research Center, Toyobo Co., Ltd., 1-1 Katata 2-chome, Ohtsu 520-02, Japan
}

(Received March 25, 1996)

\begin{abstract}
Crystallization properties of the copolymers of poly(ethylene terephthalate) (PET) comprising small amount of 4,4'-isopropylidenediphenol (bisphenol-A) and bis(4-hydroxyphenyl)sulfone (bisphenol-S) units were compared by isothermal crystallization with the time-resolved light scattering method. These copolyesters were prepared from PET, terephthalic acid and diol diacetates by acidolysis reaction and following polycondensation. The copolymers showed a spherulite growth like PET homopolymer, though their crystallization rates decreased and induction times increased with increase in comonomer content. An accelerated nucleation, which was observed in the case of some rigid arylate units-containing copolyesters, was not detected in these copolymers. The bisphenol-S-containing copolymers showed lower crystallizability than the corresponding bisphenol-A-containing copolymers.

KEY WORDS Poly(ethylene terephthalate) / Bisphenol-A / Bisphenol-S / Copolymers / Crystallization Rate / Isothermal Crystallization /
\end{abstract}

Crystallizability of polymers is usually decreased by copolymerization. This is because the regular chain packing for crystallization is inhibited by the introduction of comonomer segments. In previous papers, ${ }^{1,2}$ however, it was found that certain arylate-unit-containing poly(ethylene terephthalate (PET) copolymers showed increased crystallizability compared to PET homopolymer.

The papers described about the crystallization properties of PET copolymers comprising 4,4'-biphenylene terephthalate unit or paraphenylene terephthalate unit. In these systems, the copolymers with very low level of the comonomer content such as $2 \mathrm{~mol} \%$ showed the crystallization rate slower than that of PET. When the comonomer content increased, increased nucleation density and appearance of smaller and irregular spherulites were observed. As a result, at first, an increase in the crystallization rate was observed at lower region of the crystallization temperature, then more higher content of the comonomers around $10 \mathrm{~mol} \%$ gave the crystallization rates higher than those of PET at a whole range of the crystallization temperature. These two copolymer systems showed similar crystallization tendency, however, the copolymers containing paraphenylene terephthalate unit needed higher comonomer content to display a remarkable increase in the crystallization rate than the copolymers containing $4,4^{\prime}$-biphenylene terephthalate unit.

The biphenylene terephthalate and paraphenylene terephthalate units form four and three consecutive paraphenylene moieties, respectively. The rigid characteristics of these segments may lead to a local orientation of the molecular chains on the molecular level and resulted in accelerated nucleation. In this article, in order to consider the structural effect on improvement of the crystallizability in arylate-unit-containing PET copolymers, series of PET copolymers comprising 4,4'-isopropylidenediphenol (bisphenol-A) unit and bis(4-hydroxyphenyl)sulfone (bisphenol-S) unit as aromatic diols were prepared, and their crystallization properties were investigated.

\section{EXPERIMENTAL}

\section{Materials}

Poly(ethylene terephthalate) (Toyobo, RE530), terephthalic acid (Mitsui Petrochemical Industry), bisphenol-A (Nacalai Tesque, EP), bisphenol-S (Konishi Chemical Industry) and chlorobenzene (Nacalai Tesque, GR) were used without further purification.

\section{Preparation of Diol Diacetates ${ }^{3}$}

Bisphenol-A $(50.0 \mathrm{~g}, 0.219 \mathrm{~mol})$, acetic anhydride $(150 \mathrm{ml})$ and $1 \mathrm{ml}$ of sulfuric acid were stirred at $100^{\circ} \mathrm{C}$ for $30 \mathrm{~min}$. After cooled to room temperature, the reaction mixture was poured into ice water. A white crystal obtained was collected and washed with 1 litter of $3 \%$ sodium hydroxide aqueous solution and pure water, and then dried. Recrystallization was carried out by using toluene/petroleum ether as a solvent. Yield $89 \%$. $\mathrm{mp} 96^{\circ} \mathrm{C}$.

Bisphenol-S diacetate was prepared with the same manner; Yield $66 \%$. $\mathrm{mp} 171^{\circ} \mathrm{C}$.

\section{Preparation of Copolymers}

Copolymers were synthesized from PET and equimolar combinations of terephthalic acid and the diacetate of bisphenol-A or bisphenol-S; first, acidolysis reaction of PET by the terephthalic acid occurs, then polycondensation of the carboxylic chain ends and the diol diacetate proceeds as illustrated in Scheme 1. No catalyst was added for the copolymerization to minimize influence of the residual catalyst on the crystallization properties of the resultant copolymers. As an example, preparation of the bisphenol-A-containing copolymer with a feed ratio of $10 \mathrm{~mol} \%$ is described below.

PET $(19.2 \mathrm{~g}, 0.100 \mathrm{~mol})$, terephthalic acid $(1.84 \mathrm{~g}$, $0.0111 \mathrm{~mol})$, bisphenol-A diacetate $(3.47 \mathrm{~g}, 0.0111 \mathrm{~mol})$ and $10 \mathrm{ml}$ of chlorobenzene were placed in a glass vessel 


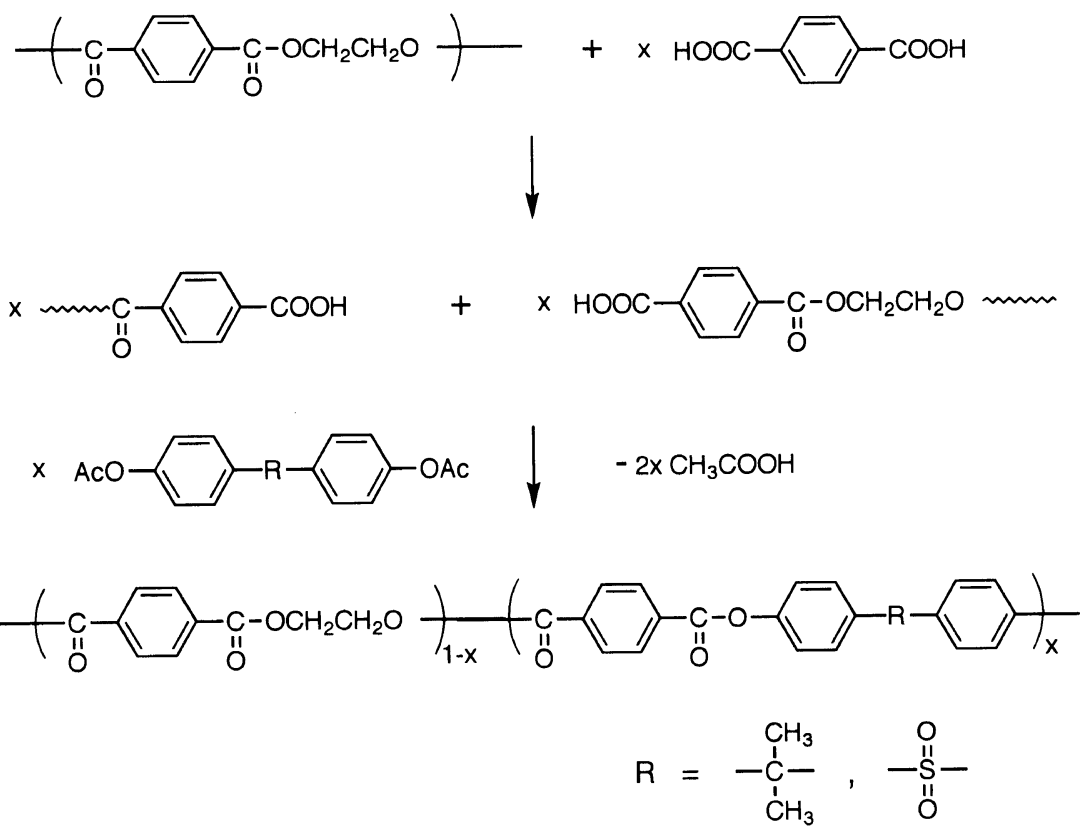

Scheme 1.

at $150^{\circ} \mathrm{C}$ under nitrogen flow. The mixture was heated to $280^{\circ} \mathrm{C}$ and kept at the temperature for $30 \mathrm{~min}$ with stirring to proceed acidolysis reaction. Then, vacuum was applied gradually to reach $0.3 \mathrm{mmHg}$ in $30 \mathrm{~min}$, and the polymerization was continued for 3 hours.

Other copolymers were prepared by the same procedure except changing the comonomer feed ratio.

\section{Characterization}

Reduced viscosities were measured at a concentration of $0.4 \mathrm{~g} \mathrm{dl}^{-1}$ in a mixed solvent of $p$-chlorophenol and 1,1,2,2-tetrachloroethane $(3: 1, \mathrm{vol} / \mathrm{vol})$ at $30^{\circ} \mathrm{C}$. GPC measurement was performed on a Shodex GPC system-21 with Tosoh columns $\mathrm{GMH}_{\mathrm{XL}}-\mathrm{GMH}_{\mathrm{XL}}-\mathrm{G} 2000 \mathrm{H}_{\mathrm{XL}}$ (calibrated by polystyrene standards). The working temperature was $40^{\circ} \mathrm{C}$, the solvent was a $98 / 2$ mixture of chloroform and hexafluoroisopropanol and the detection was absorption at $254 \mathrm{~nm}$. ${ }^{1} \mathrm{H}$ NMR spectra were obtained in a mixed solvent of dichloromethane- $d_{2}$ and deuterated trifluoroacetic acid with a Varian Gemini-200 spectrometer. Thermal transition temperatures were determined by using a differential scanning calorimeter (DSC) (Perkin-Elmer DSC-7) at a heating rate of $20^{\circ} \mathrm{Cmin}^{-1}$ and a cooling rate of $10^{\circ} \mathrm{C} \mathrm{min}^{-1}$ under flowing nitrogen for quenched samples from the melt. When equilibrium melting temperatures were determined, each polymer was isothermally crystallized at several temperatures for 1 hour before DSC measurement. Thermogravimetric analysis (TGA) was conducted at a heating rate of $10^{\circ} \mathrm{C} \mathrm{min}^{-1}$ under flowing air or nitrogen using a thermogravimetric analyzer (Shimadzu TGA-50). Wide angle X-ray diffraction (WAXD) was conducted on a Rigaku rotating-anode generator (RV200) and a scintillation counter with Nickel-filtered $\mathrm{Cu}-\mathrm{K}_{\alpha}$ radiation $(40 \mathrm{kV}, 100 \mathrm{~mA})$. Optical microscopic observation was carried out on a Nikon Type OPTIPHOT2POL polarized-light transmission microscope.
Isothermal Crystallization with Time-Resolved Light Scattering

Time-resolved light scattering was carried out with a light scattering apparatus described in the previous paper. ${ }^{1}$ A sample was kept at $300^{\circ} \mathrm{C}$ for 2 min between two pieces of cover glass to form a completely melt film (thickness: $c a .30 \mu \mathrm{m}$ ), and quickly transferred onto a hot stage (Linkam TH-600PH) of the light scattering apparatus set at a crystallization temperature. Change of the angular distribution of scattering intensity under cross-polarized $\left(H_{\mathrm{v}}\right)$ optical alignment with time was recorded.

\section{RESULTS AND DISCUSSION}

\section{Characterization of Copolymers}

As no catalyst was added for the copolymerization, the copolymers obtained showed relatively low solution viscosities $\left(\eta_{\mathrm{sp}} / c\right)$ around 0.3 . The polymer compositions were determined by ${ }^{1} \mathrm{H}$ NMR. As small amount of the comonomers sublimed during the copolymerization, each copolymer contained $c a .80 \mathrm{~mol} \%$ of the comonomers fed. All the polymerization proceeded as a homogeneous and transparent melt. Table I summarizes the results of preparation of four copolymers with the comonomer feed ratio of 10 and $20 \mathrm{~mol} \%$ for each diol component: They are abbreviated as TA-BA-8, TA-BA-16, TA-BS-8, and TA-BS-16 by using the content of aromatic diol unit in the copolymers determined by ${ }^{1} \mathrm{H}$ NMR.

As shown in Table I, the melting temperature decreased with increase in comonomer content. This tendency was also seen in equilibrium melting points $\left(T_{\mathrm{m}}{ }^{0}\right)$ for the copolymers, which were evaluated by the HoffmanWeeks treatment ${ }^{4}: T_{\mathrm{m}}{ }^{0}$ is determined as an intersection of the extrapolation of the plots for $T_{\mathrm{m}}$ versus crystallization temperature $\left(T_{\mathrm{c}}\right)$ and the line for $T_{\mathrm{m}}=T_{\mathrm{c}}$. The results are shown in Figure 1. Compared to $T_{\mathrm{m}}{ }^{0}=$ $280^{\circ} \mathrm{C}$ for PET, the copolymers showed lower $T_{\mathrm{m}}{ }^{0} \mathrm{~s}$ : TA-BA-8, $260^{\circ} \mathrm{C}$; TA-BA- $16,236^{\circ} \mathrm{C}$; TA-BS-8, $248^{\circ}$ C; 
Table I. Preparation and properties of TA-BA and TA-BS copolymers

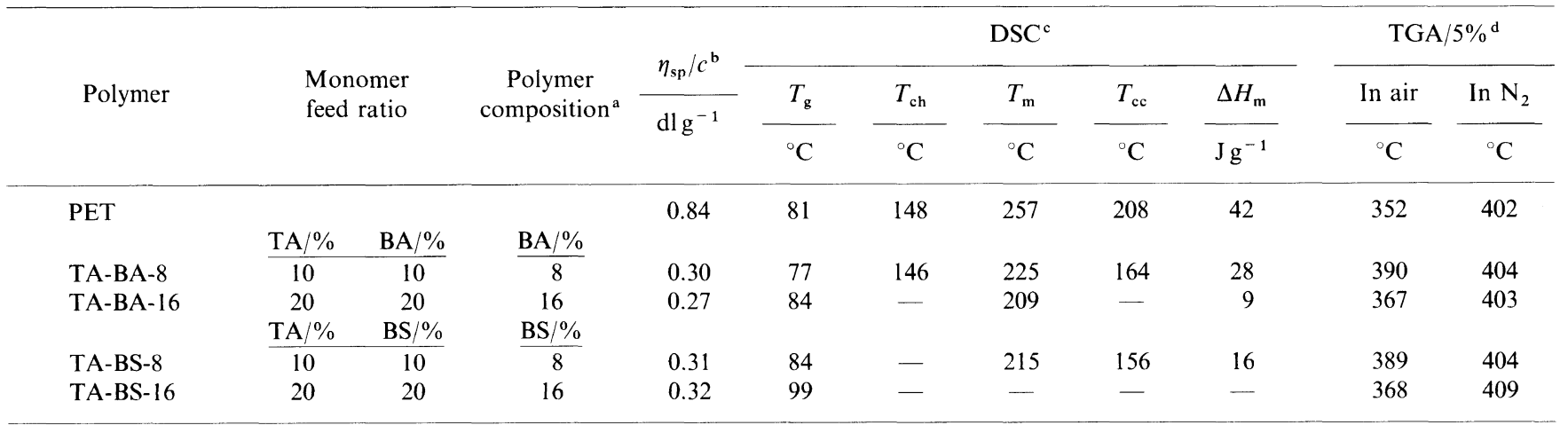

${ }^{\mathrm{a}}$ Molar content of comonomer unit determined by ${ }^{1} \mathrm{H}$ NMR. ${ }^{\mathrm{b}}$ Reduced viscosity measured at a concentration of $0.4 \mathrm{gdl}{ }^{-1}$ in $p$ cholorophenol/1,1,2,2-tetrachloroethane (3/1). ${ }^{\mathrm{c}}$ Measured at a heating rate of $20^{\circ} \mathrm{Cmin}^{-1}$ and a cooling rate of $10^{\circ} \mathrm{C}$ min ${ }^{-1}$ in nitrogen; $T_{\text {ch }}$, crystallization temperature with heating from the glass, $T_{\mathrm{cc}}$, crystallization temperature with cooling from the melt, $\Delta H_{\mathrm{m}}$, heat of fusion. ${ }^{\mathrm{e}} 5 \%$ weight loss temperature determined at a heating rate of $10^{\circ} \mathrm{C} \mathrm{min}^{-1}$.

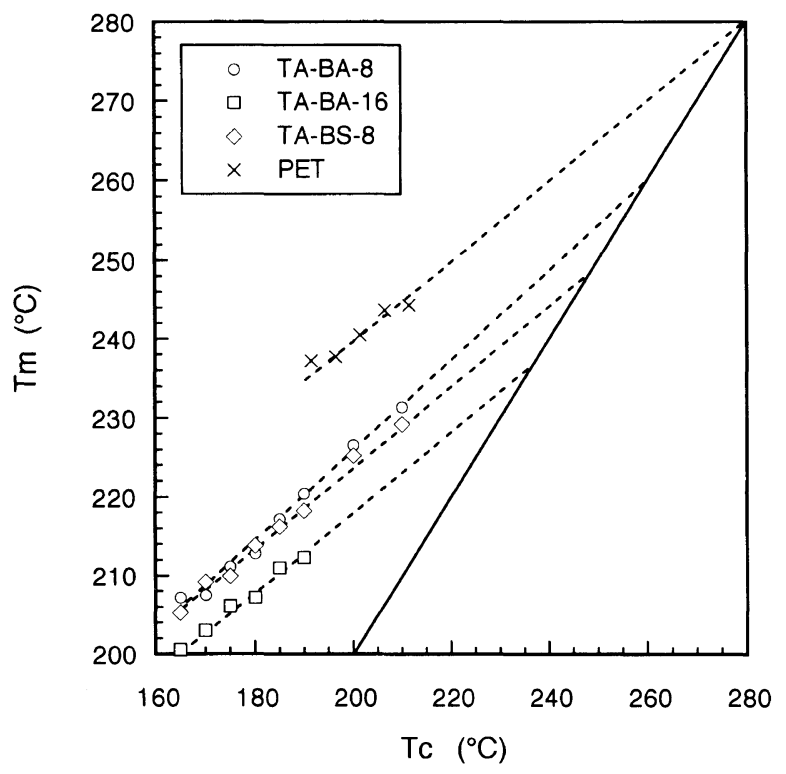

Figure 1. Hoffman-Weeks plot of PET and copolymers.

Table II. Molecular weights of PET and copolymers determined by GPC

\begin{tabular}{lcrc}
\hline Polymer & $\bar{M}_{w}$ & $\bar{M}_{n}$ & $\bar{M}_{w} / \bar{M}_{n}$ \\
\hline PET & 53900 & 15500 & 3.5 \\
TA-BA-8 & 16000 & 6400 & 2.5 \\
TA-BA-16 & 16200 & 6500 & 2.5 \\
TA-BS-8 & 14400 & 5900 & 2.4 \\
TA-BS-16 & 15000 & 6200 & 2.4 \\
\hline
\end{tabular}

no melting peak for TA-BS-16. With incorporation of the comonomers, the crystallization temperature from the melt $\left(T_{\mathrm{cc}}\right)$ decreased or disappeared and the crystallization temperature from the glass $\left(T_{\mathrm{ch}}\right)$ disappeared. These results reveal that the crystallizability of PET was lowered by copolymerization with these comonomers. As shown in Table II, the molecular weights of the copolymers were lower than that of PET. Therefore, the crystallizability should increase from the view point of the effect of molecular weight. However, the influence of molecular weight was overcome by the structural effect.

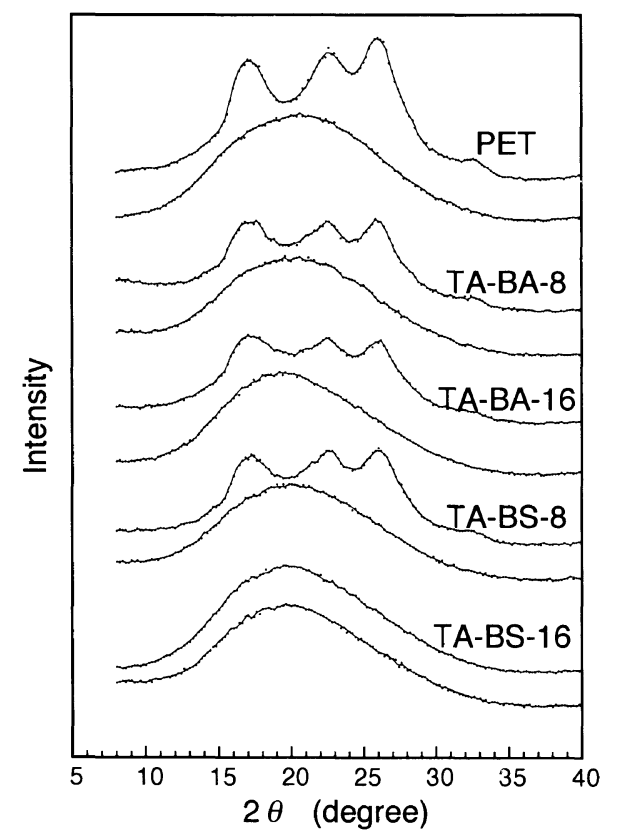

Figure 2. Wide angle X-ray diffractograms of PET and copolymers: upper, crystallized at $170^{\circ} \mathrm{C}$ for 1 hour; lower, quenched from the melt.

\section{Crystallization Properties of Copolymers}

Wide angle X-ray diffraction was measured to study the crystalline structure of the copolymers. The measurements were carried out for the samples annealed at $170^{\circ} \mathrm{C}$ for 1 hour. TA-BA-8, TA-BA-16, and TA-BS- 8 showed the same diffraction pattern as that of PET (Figure 2). Although it can not be concluded by these data only that the arylate segments were segregated from the crystal domain, it is considered that the crystal consisted mainly of ethylene terephthalate segments. These polymers showed isotropic melt, and totally amorphous samples were obtained by quenching the melt samples with liquid nitrogen. On the other hand, TABS-16 showed no apparent peak to show the existence of crystalline phase even if longer annealing time was applied.

Spherulite growth was detected by polarized microscopic observation and light scattering for the crystallization of each copolymer except for TA-BS-16. Figures 3 and 4 show the light scattering profiles of isothermal crystallization of TA-BA-8 and TA-BS-8, respectively, 

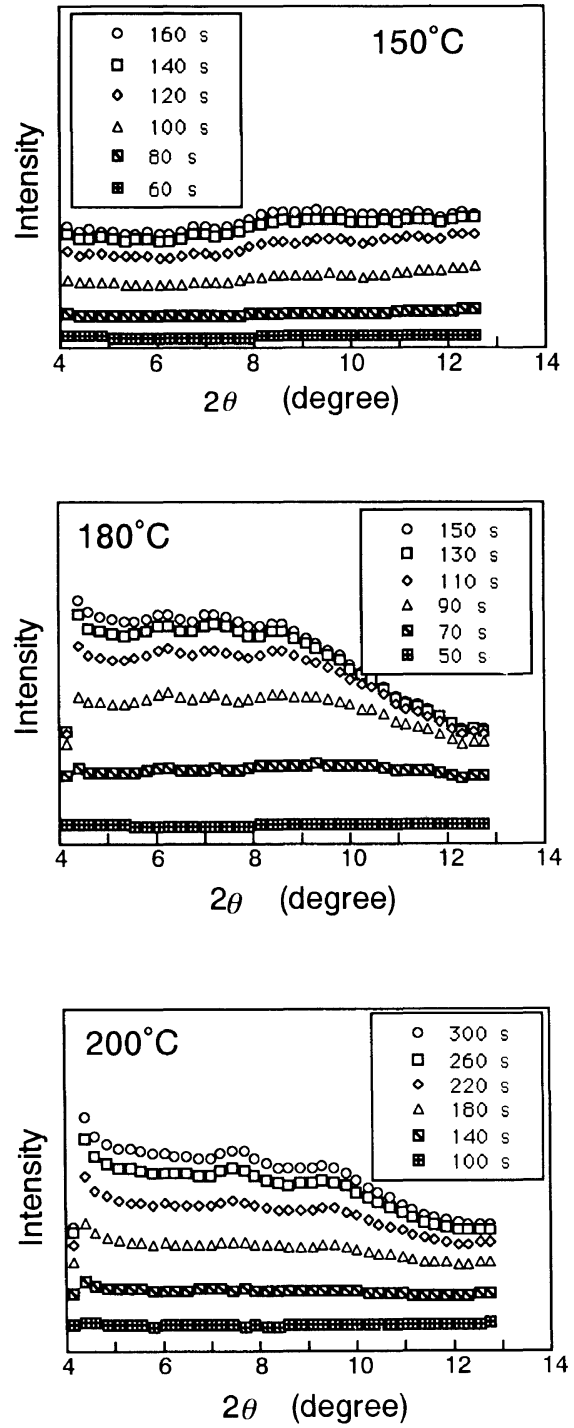

Figure 3. Time dependence of light scattering profile of TA-BA-8 under isothermal crystallization at 150,180 , and $200^{\circ} \mathrm{C}$, at an azimuthal angle of $45^{\circ}$ under $H_{\mathrm{v}}$ optical alignment.

at 150,180 , and $200^{\circ} \mathrm{C}$ at an azimuthal angle of $45^{\circ}$ under $H_{\mathrm{v}}$ optical alignment. Under two dimensional observation, a four-leaf clover pattern was clearly observed at lower crystallization temperatures, and the pattern changed to ring shape at higher crystallization temperatures.

Figure 5 shows the light scattering profiles of isothermal crystallization of TA-BA- 16 at $150,180^{\circ} \mathrm{C}$ at the azimuthal angle of $90^{\circ}$. In this system, a four-leaf clover pattern was observed at 0 and $90^{\circ}$, while PET and the other copolymers showed it at $45^{\circ}$. A deviation of the optical axis might be induced by increased content of bisphenol-A unit in this copolymer.

Invariant $Q_{\mathrm{d}}$ of the scattering intensity for $H_{\mathrm{v}}\left(I_{H_{\mathrm{v}}}\right)$ is defined as eq $1^{5}$ and has a relation expressed by eq 2 ,

$$
\begin{gathered}
Q_{\mathrm{d}}=\int I_{H_{\mathrm{v}}} q^{2} \mathrm{~d} q \\
Q_{\mathrm{d}} \propto\left\langle\delta^{2}\right\rangle=f_{\mathrm{c}}\left(\alpha_{1}-\alpha_{2}\right)^{2}
\end{gathered}
$$

where $q$ is the magnitude of the scattering vector, $\left\langle\delta^{2}\right\rangle$ is the mean-square anisotropy, $f_{\mathrm{c}}$ is the volume fraction of the crystalline domain, and $\alpha_{1}$ and $\alpha_{2}$ are the principal polarizabilities of the crystal lamella. Here, $f_{\mathrm{c}}$ at time $t$
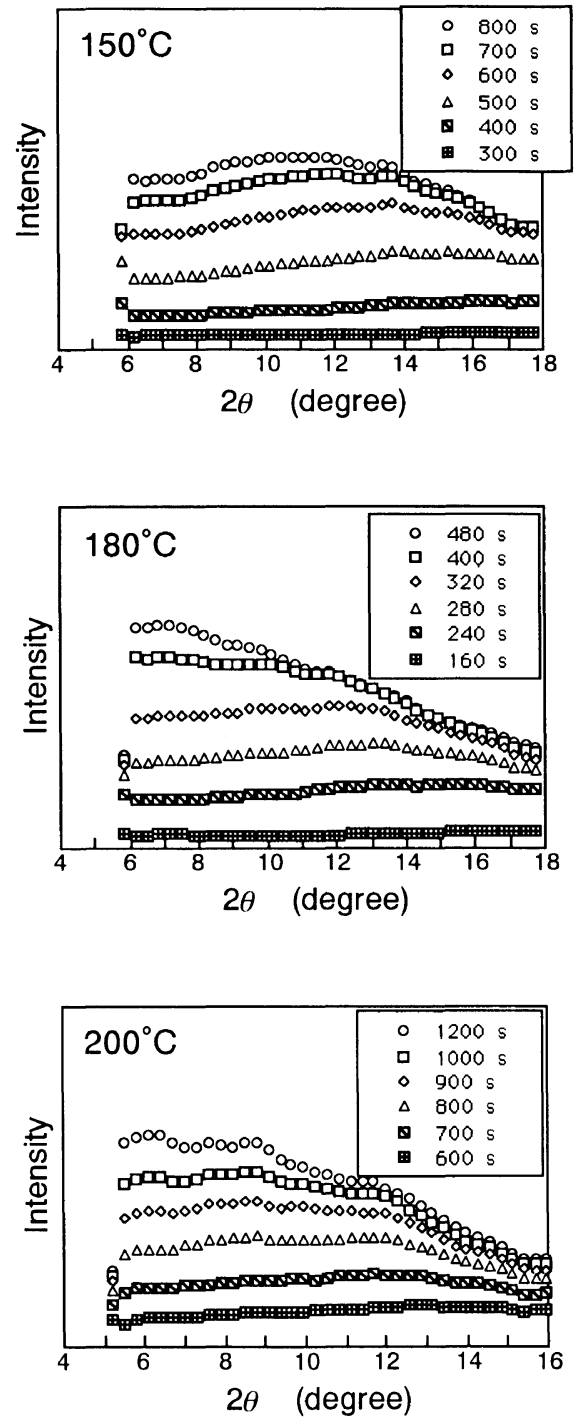

Figure 4. Time dependence of light scattering profile of TA-BS-8 under isothermal crystallization at 150,180 , and $200^{\circ} \mathrm{C}$, at an azimuthal angle of $45^{\circ}$ under $H_{\mathrm{v}}$ optical alignment.

is given by eq 3 ,

$$
f_{\mathrm{c}}(t)=Q_{\mathrm{d}}(t) / Q_{\mathrm{d}}(\infty)
$$

where $Q_{\mathrm{d}}(\infty)$ is the attainable crystallinity in the crystalline domain at a given crystallization condition. From these relations, information on the crystallization kinetics in terms of $f_{\mathrm{c}}$ can be obtained from the time variation of $Q_{\mathrm{d}} \cdot Q_{\mathrm{d}}$ increased gradually with time after a certain induction time $\left(t_{0}\right)$.

Overall crystallization rate was determined from the slope of $Q_{\mathrm{d}}(t) / Q_{\mathrm{d}}(\infty)(\mathrm{d} Q / \mathrm{d} t)$ in the crystallizing region. Figure 6 compares the overall crystallization rates of the four polymers at various crystallization temperatures. The crystallization rate of the copolymers was smaller than that of PET in the whole range of crystallization temperatures due to the reduction of regularity in the chain sequence. TA-BA- 16 showed much smaller $\mathrm{d} Q / \mathrm{d} t$ than TA-BA-8. Although the molecular weights of the copolymers were lower than that of PET, the structural effect induced by the comonomers was dominant to determine the crystallization rate. As TA-BS- 8 showed smaller $\mathrm{d} Q / \mathrm{d} t$ than TA-BA-8, the structural effect was different depending on the comonomer structure. 

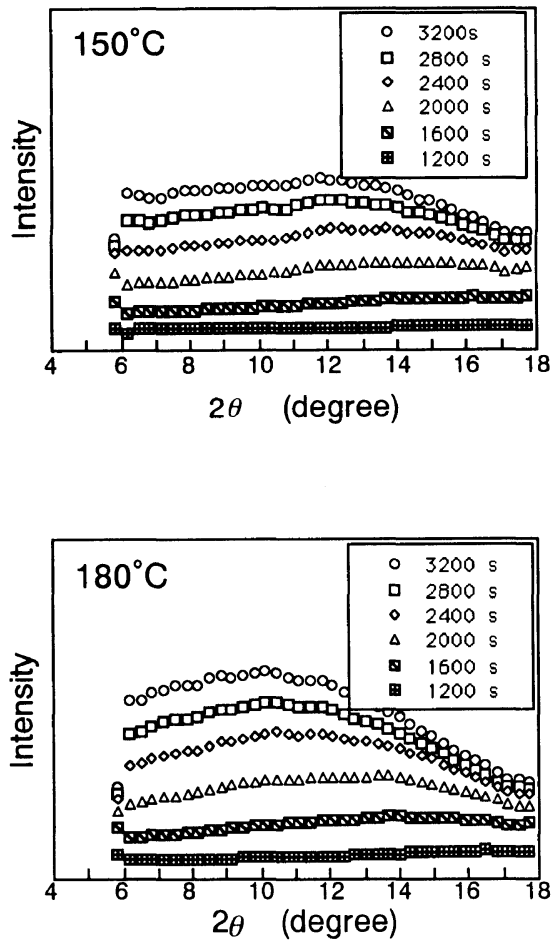

Figure 5. Time dependence of light scattering profile of TA-BA-16 under isothermal crystallization at 150 and $180^{\circ} \mathrm{C}$, at an azimuthal angle of $90^{\circ}$ under $H_{\mathrm{v}}$ optical alignment.

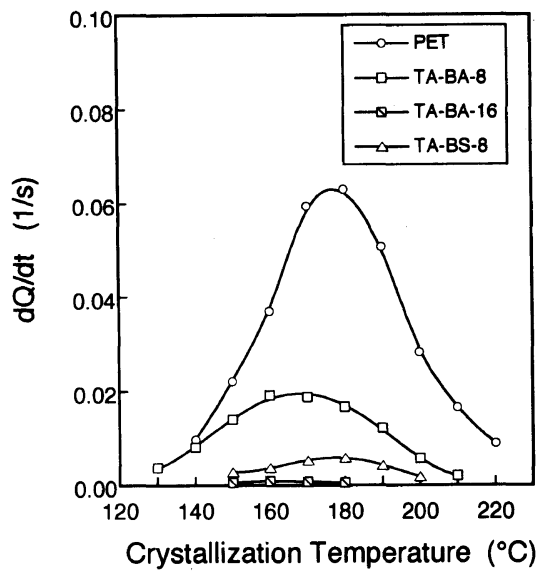

Figure 6. Temperature dependence of overall crystallization rate $(\mathrm{d} Q / \mathrm{d} t)$ of PET and copolymers under isothermal conditions.

Change in the induction time with crystallization temperature is illustrated in Figure 7. Inverse relation was observed between the induction time and the crystallization rate. As reported previously, ${ }^{1,2}$ the copolyesters containing biphenylene terephthalate or paraphenylene terephthalate unit showed remarkably short induction time when they showed the crystallization rate higher than that of PET. Such an effect was not observed in the bisphenol-A and bisphenol-S-containing copolymers. These comonomer segments just restricted the regular chain alignment of PET segments, and had no effect to enhance the crystal nucleation.

Crystallization kinetics for polymers has been approximately described by the Avrami equation ${ }^{6}$ shown below,

$$
f_{\mathrm{c}}=1-\exp \left(-k\left(t-t_{0}\right)^{n}\right)
$$

where $k$ is the rate constant and $n$ is the Avrami index

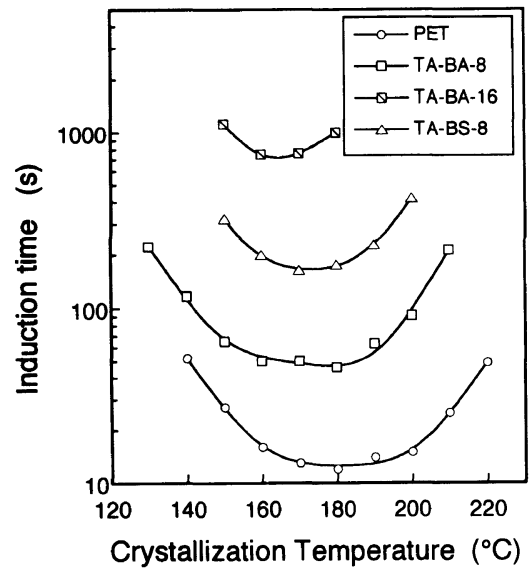

Figure 7. Temperature dependence of induction time of PET and copolymers under isothermal conditions.

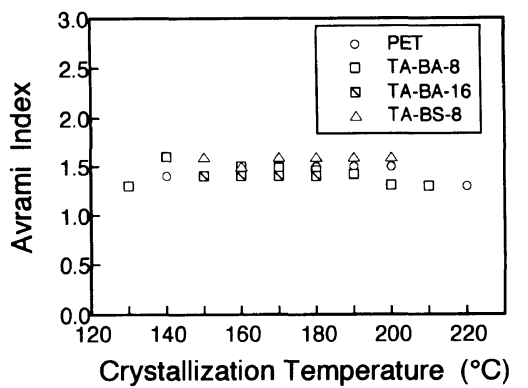

Figure 8. Temperature dependence of the Avrami index for PET and copolymers.

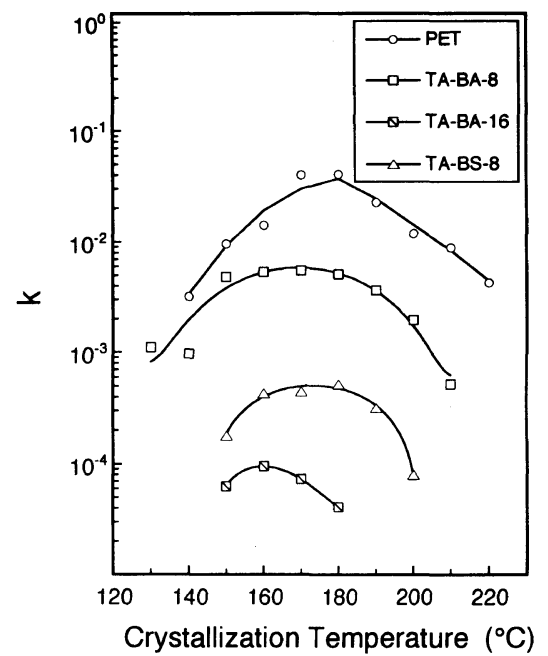

Figure 9. Temperature dependence of the crystallization rate $(k)$ derived from Avrami treatment for PET and copolymers.

related to the geometry and mode of crystal growth. The equation for Avrami plot is obtained from eq 3 and 4.

$$
\ln \left(-\ln \left(1-Q_{\mathrm{d}}(t) / Q_{\mathrm{d}}(\infty)\right)\right)=\ln k+n \ln \left(t-t_{0}\right)
$$

The kinetic parameters are obtained by plotting the data according to eq 5; the slope is equal to $n$ and the intercept is equal to $\ln k$.

Figure 8 shows the Avrami index obtained for the polymers. Almost constant $n$ values around 1.5 were obtained for each polymer independent of crystallization temperatures. These results mean the crystallization mechanism for these polymers was the same. The value, $n=1.5$, is the same with the PET copolymers comprising 
$4,4^{\prime}$-biphenylene terephthalate unit or paraphenylene terephthalate unit as described in the previous papers. ${ }^{1,2}$ Although this is smaller than the values previously reported for PET, $n=2.5-3.0,{ }^{7-9}$ it is attributed to the selection of $\left(t-t_{0}\right)$ as the measuring time instead of $t$.

The rate constants $(k)$ obtained by Avrami analysis are illustrated in Figure 9. Dependence of $k$ on the polymer structure and crystallization temperature was nearly consistent with that of the overall crystallization rate determined from $\mathrm{d} Q / \mathrm{d} t$.

As a conclusion, the existence of bisphenol-A and bisphenol-S units in PET disturbs the crystallization of the copolymers. These comonomers did not induce any remarkable change in the crystal formation of PET, while an accelerated crystal nucleation was observed when 4,4-biphenol and hydroquinone were incorporated. It is considered that flexibility and bulkiness of bisphenol-A and bisphenol-S has no effect on the local orientation of the molecular chains. From these results, it is clear that the structure of the comonomers is important to modify the crystallization properties of PET.

Acknowledgments. The author is grateful to $\mathrm{Mr}$. Yoshinori Nakae of Toyobo Co., Ltd. for GPC measurements.

\section{REFERENCES}

1. Y. Sakaguchi, M. Okamoto, and I. Tanaka, Macromolecules, 28, 6155 (1995).

2. Y. Sakaguchi, Polymer, in press.

3. M. Levine and S. C. Temin, J. Polym. Sci., 28, 179 (1958).

4. J. D. Hoffman and J. T. Weeks, J. Res., Natl. Bur. Stand., 66-A, 13 (1962).

5. J. Koberstein, T. P. Russell, and R. S. Stein, J. Polym. Sci., Polym. Phys. Ed., 17, 1719 (1979).

6. M. J. Avrami, J. Chem. Phys., 7, 1103 (1939).

7. V. E. Reinsch and L. Rebenfeld, J. Appl. Polym. Sci., 52, 649 (1994).

8. D. Garcia, J. Polym. Sci., Polym. Phys. Ed., 22, 2063 (1984).

9. S. A. Jabarin, J. Appl. Polym. Sci., 34, 85 (1987). 